\title{
Mapping Historical Texts in the Classroom: The Anatolian Travelers Project
}

The process of mapping provides an active approach for students to engage with landscapes of the past. As part of a graduate-level class called Spatial Analysis of the Past, students were given an assignment to create online maps of nineteenth-century travelers' accounts about western Anatolia (Turkey). Travelers often record their experiences of journeying through foreign landscapes. Although usually written from the perspective of an outsider, these first-hand accounts can serve as valuable primary source documents for geographical information about these regions. The participation of students in mapping these accounts can prompt deep reflection in the classroom regarding the subjectivity of spatial representations and understandings. This class assignment served as the initial step in a larger research undertaking called the Anatolian Travelers Project, an ongoing, open access initiative. This project attempts to collect, organize, and visualize regional travelers' accounts through online mapping, to improve our understanding of how people interacted with this landscape and its inhabitants. The project records and compares, among other things, the travelers' modes of transportation, the routes they chose, their observations about the land and people, and what they felt was worth recording and publishing. Here, we reflect on the use of web mapping as a pedagogical method in teaching the past by reporting on the results of our classroom experimentations. Specifically, we focus on four learning goals: the integration of historical and archaeological methods, an increase in digital literacy among humanities students, experimentation with visualization decisions, and an investigation of landscape and spatial perspectives. Our experiences in the classroom will help inform our future implementations of online mapping as a teaching tool. In terms of technology, we utilized the Neatline plugin to Omeka for mapping, though we consider infrastructure ultimately interchangeable.

\section{PROJECT BACKGROUND}

The Anatolian Travelers Project developed from our archaeological research on diachronic human movement through the landscapes of western Anatolia (Cobb 2016). This region has always been an important area of transit from the Aegean coast to the central Anatolian plateau, and is traversed by east-west river valleys separated by stark mountain ranges (Figure 1). Due to the region's long history of habitation and migration, it is necessary to utilize multiple approaches to understand the relationship between people and place. Archaeologists already commonly leverage a variety of methods to study movement, from the digital analysis of paths over surface models, to the phenomenological experience of the landscapes today (David and Thomas 2008). Yet travelers' accounts can provide a different perspective on these areas and how people traveled through them, reflecting the authors' varied circumstances, motivations, and decision-making factors. These texts can provide a qualitative dataset for travel prior to modern forms of transportation, potentially serving as analogues for the prehistoric movement patterns and landscape interactions that are of interest to archaeologists.

Western Anatolia is fortunate to have a long tradition of attracting visitors who documented their experiences in 


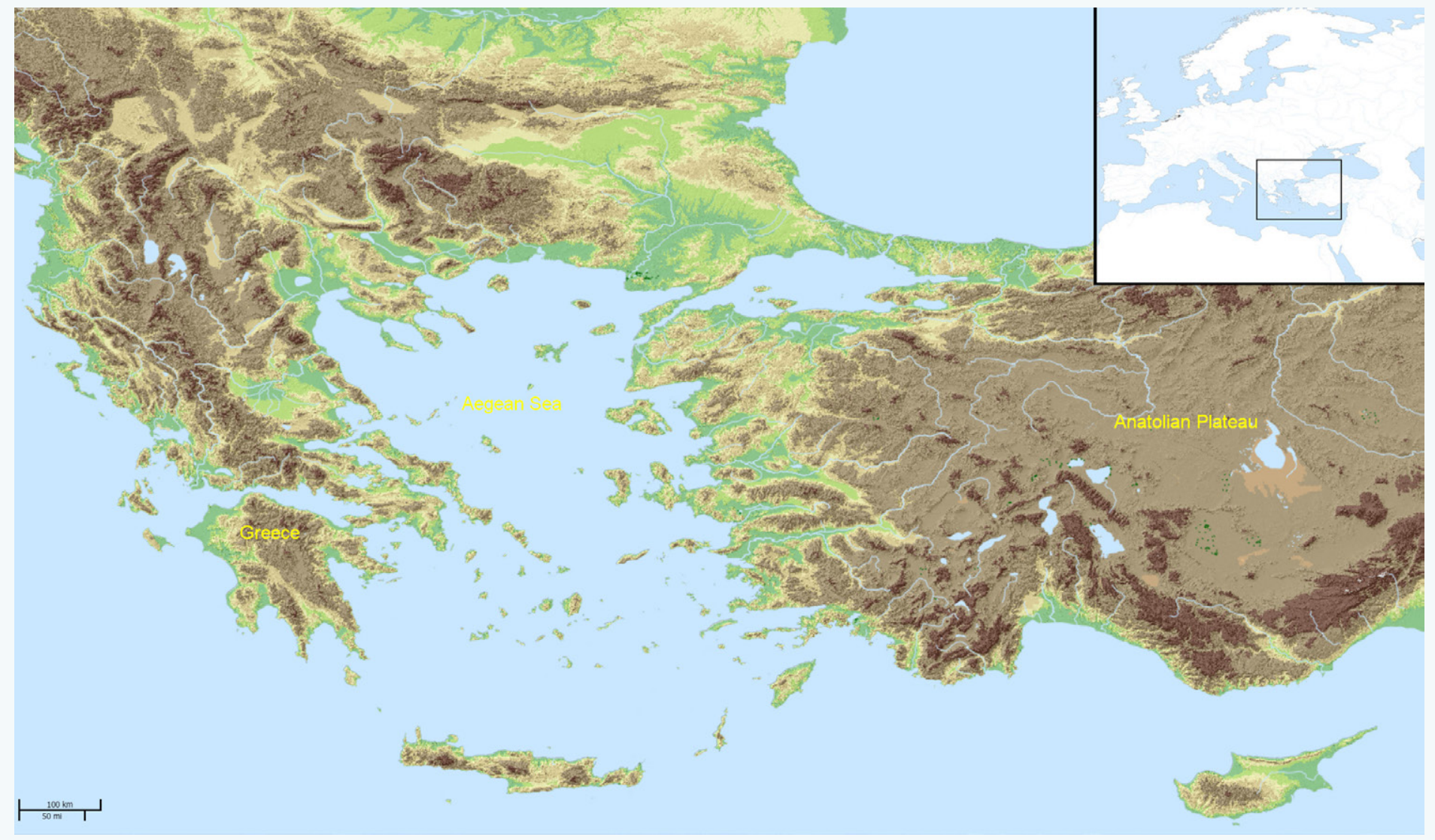

Figure 1. Map of western Anatolia, from the Ancient World Mapping Center's Antiquity À-la-carte.

the region. Thousands of years ago, it was the subject or setting of a wide-ranging set of works, including Hittite military annals and Xenophon's Anabasis (Landry and MacLean 2012). In both cases, interest lay less in the landscape itself than in the actions that took place there. For the Hittite kings, western Anatolia was a liminal zone, marked by struggles with peoples referred to in Hittite texts as "Arzawa" and "Ahhiyawa," the latter possibly referring to Mycenaean (“Achaean") Greeks (Beckman 2016). Xenophon's account of travel through the region shares this military emphasis: it focuses primarily on the arduous journey of his army, recording place names and distances but little other information about the landscape (Purves 2002; Stoneman 2015). Yet during the Ottoman period, especially throughout the sixteenth to nineteenth centuries CE, the area attracted a significant number of European author-travelers who were drawn to the region for a wider variety of reasons, prominent among which was the region's classical past and its Biblical connections-for instance, as the location of the book of Revelation's Seven Churches of Asia (Mellink 1966; Robert 1980).

Our project set out to gather these and other accounts for detailed analysis of western Anatolia. By mapping each account, we both visualize the individual narratives and enable the spatial comparison of multiple voyages by different travelers, including those from different chronological periods. Over time, we hope to build a comprehensive dataset of travelers and their written responses to this region. The Anatolian Travelers Project serves as an online, open access platform for creating and sharing digital maps of these historical accounts. The Penn Libraries have provided the software infrastructure to support and sustain our project over the long term. We hope that these maps can serve as the foundation for future class-based projects interested in addressing some of these same pedagogical and theoretical issues, for research endeavors focusing on human interaction with the landscape of western Anatolia in any period, and perhaps as a model for scholars documenting travelers' movements in other regions.

Although our project has multiple ultimate research goals, our first practical step was a classroom assignment for the Spatial Analysis of the Past graduate-level class taught at the University of Pennsylvania in the spring of 2017. This assignment provided the opportunity for us to reflect on experimenting with mapping texts in the classroom, the subject of this paper. We hope our observations 
will contribute to ongoing conversations in the literature about teaching through mapmaking (Sack 2018; Huffman 2018). The first section below provides a more detailed overview of the project's goals, and especially our initial pedagogical objectives. Next, we discuss a range of similar research on mapping texts and the past. Then we provide an overview of our online tool selection process, to highlight the tradeoffs during implementation. A subsequent section outlines the text mapping assignment the students undertook in the classroom. Finally, we end with a reflection on our experience with this teaching and learning experiment, by considering how online mapmaking with historical texts impacts students in the classroom.

\section{PROJECT GOALS}

As WiTh ANY Digital humanities undertaking, the Anatolian Travelers Project was designed to serve a variety of functions. We intend for this to be a long-term project, and thus we plan to achieve these multiple goals iteratively as we proceed. For this classroom experiment, our first concern was to deal specifically with different tools and methods that could encourage and enable learning in a classroom environment. In this section, we outline the specific pedagogical goals of implementing the initial part of this project as a class assignment. First, however, we provide further details about our ultimate goals of landscape research, data collection, and information sharing. Although not mutually exclusive outcomes, current digital methods do place some limitations on our ability to achieve a proper balance among these objectives. For the moment, however, these motivations contextualized our classroom decisions, from the immediate learning objectives to tool and text selection.

The original genesis of the project was a desire to better understand the archaeological landscapes of western Anatolia. The maps, as the final product of our project, will help us address several research questions regarding human movement through western Anatolia, including during prehistoric time periods. First, we aim to interrogate our sources to understand why historic travelers came to this region and described it, and how they conceived of what they saw and experienced on a phenomenological level. Second, we will study the logistics of transportation, including the means of travel, the choices made about the routes of movement, and possible motivations for travel. This region could be crossed by horse, cart, or foot, and the choice understandably affected the routes each traveler chose. Yet route choices may also have involved practical and environmental concerns, such as the avoidance of flooded rivers, lack or dilapidation of infrastructure and other safety concerns, or interactions with local inhabitants that may have impacted access to certain locations. Third, we want to record what these travelers noticed along the way: what drew their interest and with whom did they interact? The lived experience of moving through a landscape reflects a variety of factors that we hope to capture through the compilation of as many narratives (datasets) as possible. Some of these factors may be consistent through time in the same landscape, so understanding movement in historic periods can inform us about movement in previous periods. In these ways, the maps will help address our goals of supporting both the prehistoric archaeological research of the region and the historical research about travelers.

To form the foundation for our research, another major goal of the project is to collect and share data about this region's past. Comparing travelers' accounts can be challenging, given the diversity of spellings and toponyms used by different authors. However, by mapping the texts, we began to standardize the way space was presented. Thus, it became easier to determine that multiple authors visited the same place, even if they named it differently. Pedagogically, this act of standardization foregrounded the students' roles in curating and interpreting data as a necessary byproduct of the mapping process.

Ultimately, we hope that by sharing these data online, we will enable further research on travel in this region that engages explicitly with the choices of the individual student mapmakers. Another researcher looking at this region could use the maps made by the students, and hopefully gain insights from those maps. At the same time, since each student made different choices about how to visualize the data, these choices will impact the subsequent research. Since these travel accounts are all in the public domain, we are able to publish all the maps with open access, helping to advance wider initiatives in open archaeological and historical research. Although this project began in the classroom, a few students took on larger roles beyond the class. One managed Penn Museum volunteers' further addition of maps and data to the project, 
and another graduate student supervised an undergraduate work-study student during a subsequent semester to finalize the maps. We intend to continue to develop the maps and add data over time.

Although we were ultimately motivated to undertake this project due to these larger research aims, we began implementation of the project as a class assignment. In this context, our initial main goal was pedagogical, so here we introduce the specific class context for our work on the Anatolian Travelers Project. Spatial Analysis of the Past is a graduate-level course offered as part of an archaeological science curriculum, intended to build students' skills in analyzing archaeological evidence. In the spring 2017 semester, the course had an enrollment of 13 students, including two advanced undergraduates. The class covered both the practicalities of using digital tools to study space, as well as the theoretical considerations of spatial analysis in historical and archaeological contexts. Among the main tools and methods covered were 3D modeling, GIS, space syntax, and geophysical investigation. Weekly assignments, partially completed during an in-class lab session, helped build skills and encouraged students to think through theoretical issues. Each student also helped lead class discussions once during the semester and developed an online tutorial to guide other students in using a specific tool. The instructor and many of the students had primary research interests in archaeology; however, we also had a handful of students whose background was in text-based historical research. The variety of academic backgrounds strengthened our discussions of the different methods and theoretical approaches. Western Anatolia's archaeological sites and landscapes served as the setting for most assignments, chosen based on the instructor's research agenda. As with most of the topics covered in the class, this online text mapping project was originally the focus of a single week of discussion and instruction in the first half of the semester, with a subsequent assignment. Prior to reaching this point, students had engaged with GIS analysis of various types, providing a solid foundation for thinking through spatial problems. For example, the previous week saw the application of GIS route analysis to the study of travel through the landscape. This earlier work offered students a suitable segue into reading the accounts of people who had recorded their own movements through the landscape.

Our mapping of these texts had multiple learning objectives within the classroom setting. Here we outline the four main ones before revisiting them below during a discussion of the results of this pedagogical experiment. First, we aimed to construct an assignment with relevance to both the historians and archaeologists enrolled in the course, one that had the added benefit of acquainting the archaeology students with the use of historical sources, with which they have less experience in their own research. Second, the students had an opportunity to consider working with and sharing data publicly via the Internet, thereby gaining exposure to selecting and using tools for creating and publishing web maps. These assignments thus also encouraged an increase in digital literacy among the humanities students in the classroom. Third, we wanted the students to confront decisions about visualizing textual descriptions of space on a 2D map. A significant yet exciting challenge was-and continues to be-how to display the wide variety of ways in which different authors discuss their surroundings. Students experimented with several methods of representation, and our project continues to wrestle with the difficulty of cartographically conveying the uncertainty inherent in the texts. After all, we are dealing with the travelers' conceptual "maps" of the region, which will differ from the geospatial map upon which we are plotting their journeys. Nonetheless, the pedagogical value of grappling with the different levels of interpretation required to spatially render textual accounts proved to be one of the most rewarding parts of the classroom experiment. This leads to our final classroom objective: to incorporate the students' close reading of the texts, foregrounded in theoretical aspects of the perception of space, within the specific context of Europeans traveling in the Ottoman Empire. Because the text mapping assignment examined the same landscape as the archaeological assignments, the creation of textual maps also provided a new way for the students to think about travel through western Anatolia.

\section{RELATED WORK}

Fortunately for our project, over the last decade online mapping has become a normal aspect of our everyday lives, with tools like Google Maps ubiquitously utilized by contemporary travelers. Naturally, this interest in online mapping has progressed into scholarship, intersecting with multiple decades of the application of standalone two-dimensional spatial analysis tools, like GIS, for studying the past (Connolly and Lake 2006). Online 
mapping projects complement this work through an emphasis on visualization and presentation, collaborative data creation and management, and the ability to create and share ever-larger datasets that can underpin more robust research. The continued improvement of these tools increases their usability and enhances their role in digital humanities research. In order to better situate our own efforts, we review some of the current trends in mapping's application to texts and research about the past.

\section{DIGITAL INVESTIGATIONS OF ARCHIVES}

Several recent projects build on the strong tradition of text analysis in the digital humanities by pushing in the dual directions of growing datasets to study larger phenomena and focusing, at least partially, on the spatial component of the historical information. The Mapping Texts Project of Stanford University and the University of North Texas seeks to combine text-mining and geospatial visualization methods to search for meaning in large, historic newspaper datasets (Torget et al. 2011; mappingtexts.org). Efforts thus far have focused on mapping the quantity and digitization quality of the newspapers, as well as locating variations in language patterns across Texas. The online visualizations combine timelines with mapped circles that vary in size or color to represent newspaper data.

A narrative-centric spatial analysis is provided by Vincent Brown's Slave Revolt in Jamaica, 1760-1761: A Cartographic Narrative (revolt.axismaps.com), demonstrating an effective platform for visualizing history within the limitations of the available evidence. Among other innovative symbology choices, the map makes use of fading tracer lines to reflect the uncertainty of movements by the rebel slave army. Brown's work has helped to expose the strategic intelligence of the rebels, while simultaneously using colonial basemaps that reflect the spatial view of the oppressive power (Brown 2015). While Brown's project focuses on the visualization of an already existing database, other efforts have been made to create comprehensive datasets for the Atlantic slave trade as a whole. Perhaps no largescale digital history project has recently caught the attention of the general public as fully as the Trans-Atlantic Slave Trade Database, which has digitized the records of tens of thousands of slave trade sea voyages (Eltis 2007; slavevoyages.org). A popular Slate article transformed these data into an animated map of the forced transport of people from Africa to the Americas over multiple centuries (Kahn and Bouie 2015). While the interactive Slate map effectively communicates the scale and orientation of the slave trade, particularly in reference to the destination of enslaved peoples, other visualization choices raise questions concerning the transformation of meaning through the digitization of documents, such as the absence of agency from the map (Rusert 2017). Even the simple act of mapping digital slavery archives therefore brings with it both the opportunity to include narrative and experience within quantitative representations of data and the possible pitfall of producing what popular audiences may interpret as a definitive model.

In these cases, however, the emphasis of the mapping projects tends towards data visualization and publication, with the authors employing methods that support analytical interpretation of the data. Where public presentation is of greater concern, such as the Slate article, a concentration on effective storytelling through data is the primary concern. Missing from these projects is a consideration of the pedagogical value of creating these maps in the first place, especially when students participate. The Mapping Texts Project, for example, cites the participation of students in the project, but does not consider what value arises from their inclusion in the process of mapping.

\section{LITERARY GEOGRAPHY AND MAPPING NARRATIVES}

While the creation and visualization of digital archives can serve to connect large datasets with narratives, there remains a gap between the qualitative experience of individual movement and its cartographic representation. In light of this problem, a slightly different perspective on mapping texts has emerged from literary studies that investigate fictional spaces. Literary geography explores how texts describe and represent space, as well as how they produce conceptual landscapes in response to those spaces, especially through the interrelations and networks among people and places in the narratives (Alexander 2015). This field also deals with how texts are received in different parts of the world, and the related reader-author interaction via the texts (Saunders 2010). As Sheila Hones has observed, "the idea that the literary text itself can be understood as a spatial or geographical event happening in the interaction of multiple agents" has guided recent research projects that seek to understand how editors, publishers, and ultimately readers shape the metaphorical landscape of a text (Hones 2017). In the case of non-fictional travelers' accounts, these multiple vectors of representation and creation make 
their way into the narrative descriptions of travel and are influenced by the author's literary environment.

In her study on George Macdonald's novel Lilith, Dryer (2012) explores the spatial implications of the protagonist's transportation into a magical world where his choices are inscribed upon the landscape. Dryer is particularly interested in examining the lack of choice in the literary space of the labyrinth, where all choices inevitably lead to the same conclusion. This approach to mapping space creates a conceptual map, something like a "mental map," that does not attempt to accurately reflect space but rather to represent relationships between literary locations and the movements among them. Along these same lines, Caquard $(2011 ; 2013)$ surveys the interface between mapping and narrative in literature, film, fiction, and personal narratives such as blogs or oral traditions in indigenous societies. Although he finds that geospatial storytelling allows for powerful visualizations of narratives, Caquard argues that currently we are bound by our reliance on what he calls "grid maps"-commercial services such as Google Maps. These deploy satellite imagery and modern cartographic standards to produce scientifically accurate representations of space, on top of which "narratives" are mapped. This misses out, however, on the diverse narratives of spatial interaction, such as those found among indigenous societies, that do not conform to modern conceptions of mapping (c.f. Caquard et al. 2009). Our project and in-class assignment have highlighted a similar tension between representation and reality, showing that the mental landscapes of our Anatolian travelers are often difficult to pair with top-down satellite imagery.

\section{SPATIAL ANALYSIS AND VISUALIZATION}

Digital spatial analysis tools, such as GIS, have for years impacted every aspect of the historical research process (Knowles 2002). Recently, attempts have even been made to extract quantitative data from experiential narratives of travel through landscapes. For example, Murrieta-Flores, Donaldson, and Gregory (2017) have applied GIS to the study of historical works of travel writing about the English Lake District. They found that the locations mentioned by travelers, moving by cart on major thoroughfares, corresponded directly to the least-cost paths through the Lake District, indicating the importance of the natural corridors of the region to wheeled transport. Similarly, Rahman, Zaman, and Hafiz (2016) used aggregated point analysis to create boundaries for the city of Dhaka, Bangladesh based on mentions of specific and locatable places in historic texts. By comparing this map with the local geomorphology, they concluded that the texts can provide a relatively accurate idea about the boundaries of the pre-Mughal city. In both cases, the impetus towards recording data points from narrative texts serves as a model for how scholars can create and share spatial datasets from historical accounts.

There have also been previous attempts to use Neatline software in the mapping of texts. Neatline, explored in detail later, is a plugin to the open source web exhibit-building software Omeka. Evans and Jasnow (2014) used Neatline to investigate Homer's catalogue of ships in Book 2 of the Iliad (ships.lib.virginia.edu). By using novel methods of syntactic analysis to pay close attention to the relationships between place names in the text, the authors found that Homer describes accurate travel routes in the catalogue. More interestingly, the use of Neatline allowed the authors to also locate an exception to this rule that would have otherwise remained uncovered. The representational power of Neatline, the authors suggest, combined with their methodological approach, should allow previously unlocated sites mentioned in the text to be geographically determined in the future.

Other scholars have also touched on the relationship between the mapping process and the study of history in multiple contexts, with particular focus on the mode of visualization. For example, Muri (2016) highlighted the importance of spatial visualization as part of the historical research process in her work on London's Grub Street. Earley-Spadoni (2017) advocated for applying digital humanities approaches, including digital storytelling and data visualization, to archaeological studies. A prime example of the latter is the recent proliferation of network analysis studies in archaeology, where the connections among sites are foregrounded (Brughmans 2013). Thus, there are many possibilities for the visualization of data, but we also need to consider the impact of data uncertainty on visualization. MacEachren (1995) discusses several issues with attempting to deal with uncertainty during the mapping process. Color saturation of symbols, blurred or transparent symbology, and the resolution of objects can all play a part in signaling the uncertainty of a mapped feature. Yet such sophisticated graphical representations also run the risk of overwhelming both new users of the mapmaking tools, such as students, and an audience unfamiliar with unclear information. We must always take into consideration the fact that most users of the maps, who are generally untrained in critical perspectives, may view 
the results as certain because of the polished visualization, even though the underlying data are actually uncertain.

\section{TRAVELING IN ANATOLIA}

Past efforts to map Anatolia more precisely include the products of nineteenth-century German cartographers, whose works would become popular resources in the era of many of the travelers' accounts investigated by our project (Débarre 2016). While these maps were extremely useful to us for locating the toponyms mentioned in some of our texts, it is clear that the aims of these travel narratives and the cartographic representations of space in the nineteenth century were often at odds. Turning to recent work, we can find other online projects, including Travelogues: Travellers' Vierws, produced by the Aikaterini Laskaridis Foundation, which has been cataloging accounts from travelers to the Eastern Mediterranean from the fifteenth to the twentieth century as part of a larger interest in Greek heritage in the region (eng.travelogues.gr). The Anatolian section of this website provides a valuable guide for finding accounts to map. Similarly, Külzer (2016) relies on travelers' accounts to help understand routes through this region in the Byzantine period, as part of a larger effort to map the changing territory of the Byzantine Empire and movement through it. Another project called Mapping Ancient Texts is using online tools, similar to our own, to map travel narratives and correspondences, highlighting movement among sites, rather than just the sites themselves (mappingancienttexts.net). The Mapping Ancient Texts project team covers ancient authors, will likely expand their dataset to Anatolia eventually, and happily appear to intend to create a publicly accessible resource.

If we step back and consider the specific context of foreign travelers in the Ottoman Empire, we also intersect with scholarship on nineteenth-century orientalism (Said 1978). These travelers came to Anatolia with preconceived notions about what to expect in terms of the landscape, peoples, and government. Europeans considered the East a land of decadence, fallen from the height of a classical past. This is often reflected in their writings as condescension regarding the local inhabitants. Many of the author-travelers had an amateur interest in archaeology, so especially palpable can be their characterization of the treatment of local archaeological remains, including destruction (Cobb 2018). In our project, we hope to consider the impact of this orientalist milieu on foreign travelers' perceptions of space, thus contributing to larger post-colonial dialogues.

\section{THE ANATOLIAN TRAVELERS PROJECT}

Like many of these digital projects, our approach foregrounds the importance of collecting the data together in one place and visualizing the texts spatially to inform our understanding of past movements through western Anatolia. Yet we also hope to focus on all travelers who recorded this area, rather than just the most famous ones, in order to mine the "long tail" of the dataset for additional insights. For the time being, our approach is qualitative, focusing on visualization and interaction with the texts, rather than on spatial analytical approaches such as least-cost path analysis, though those are important to our wider interest in the region and to further archaeological research. By combining qualitative and quantitative approaches, we hope in particular to prevent the devaluation of individual factors impacting decision-making, especially the cultural or ideological purposes of the travel. Our project attempts to grapple with these factors while reflecting the narrative created by the author, including dealing with their own original decision to publish their journeys as texts. Like other projects, we also emphasize the open and online nature of our work both to support other researchers and to engage with the public in a more fundamental and educational way. Most immediately, however, our project hopes to foreground the pedagogical value of map creation. Many mapping projects employ student workers or utilize student resources in the classroom to collect, parse, or visualize data. Rather than treating this simply as a necessary part of any mapping project, we hope to encourage scholars and researchers to use the mapping process as a teaching opportunity with its own benefits.

\section{EVALUATION OF TOOLS}

In preparation for the Anatolian Travelers Project, the Penn Libraries evaluated several different online mapping tools for their suitability for this project's requirements. We reviewed tools that matched our use criteria with the understanding that each tool would bring with it some limitations. Since this project was starting out as an experiment with multiple goals, we realized that no one tool would be a perfect match for our project. The class 
instructor determined the most important criteria in collaboration with the digital humanities specialists at the Penn Libraries. In this way, our tool decision was driven by the necessities of the classroom setting, but guided by our vision for the project's future.

Before looking for the right tool, a researcher should ask a number of different questions: they should consider the data they are starting with, the desired final product, the team that will collaborate on the project, how to acquire the correct tool, and how to learn to use that tool effectively. Our requirements for a tool prioritized ease of use and the ability for multiple contributors to work simultaneously. Given that our intended users had limited web design and mapping experience, we sought a simple, easy-to-learn interface. Yet we wanted a powerful tool with multiple means of data input and output, without the need to invest substantial effort in customizing any part of the process. Most importantly, we sought the ability to display textual narrative alongside a map and timeline, "out of the box." Increasingly in university environments, libraries and digital humanities centers contain the expertise to assist with these types of digital collaborative projects, as was the case with the Penn Libraries.

Mapping for the humanities often falls into three separate, but related, use cases: geospatial analysis, visualization of tabular data, and storytelling. Geospatial analysis usually involves the statistical processing of vector and raster spatial datasets, often within GIS software. An example would be working with multiple types of geometry collected during an archaeological surface survey to determine the target area for a future season's fieldwork. Several types of information may also be recorded in tabular form, such as ancient trade routes or the locations of sunken ships, based both on coordinates of the findspots and associated data collected from large text corpora. Esri's ArcGIS, a powerful software suite with extensive analytical capabilities, is the most well known tool in this category. It runs only on the Windows operating system, is complex to learn, and requires a license fee. QGIS (qgis. org) is a very similar tool in terms of complexity and functionality, but is free, open source, and runs on additional operating systems. As a result, it has seen increasing popularity in the humanities over the last few years. The web application CARTO (carto.com) provides a limited subset of the analytic functionality of the main GIS platforms, but as an online tool it better supports collaboration while being free for small-scale use.
Apart from being processed and analyzed, the data must also be mapped. Often, this takes the form of static presentations of an existing dataset with little to no accompanying narrative, leaving large amounts of interpretation to the viewer. CARTO is currently the most popular platform for this type of map, enabling users to import various base maps and upload tabular data. It requires minimal understanding of web design to create professional-grade visualizations. For users interested in more complex customization, MapBox (mapbox.com) allows the creation of custom basemaps, and provides free accounts with limited functionality. Tim Waters has created the free online Map Warper (mapwarper.net) tool to crowdsource the georeferencing of historic maps, and it can be used for a variety of purposes. Researchers with minimal training in web design can also take advantage of Leaflet (leafletjs.com) for customizing user interaction with spatial data.

Storytelling, through the mapping of narratives, is a specific type of visualization that best fits the goals of the Anatolian Travelers Project. The tools we investigated included StoryMap JS (storymap.knightlab.com), an easyto-use website for highlighting the locations of a series of events. This free tool also enables maps to be embedded in other websites. Esri, too, supports an online product called Story Maps that enables the creation of exhibits using existing basemaps in their archive. This tool can exchange some data with ArcGIS and is therefore ideal for projects where the pre-existing work is already Esri-compatible, and it offers some limited free functionality. In both cases, the focus of the application is on quick and simple production of a visual narrative, with very little room for customization without significant programming experience.

The Neatline plugin to the open source Omeka content management system is also designed for storytelling and mapping narratives. We decided to utilize this software for a number of reasons. First, Omeka enables large collaborative projects and has a significant community of support. The Penn Libraries offered workshops on Omeka and Neatline, allowing the students to begin building their maps after a brief training session. In addition, without any customization, this system afforded good integration between an interactive timeline, based on an additional plugin called Simile, and the main map. Second, we could place links in the narrative text to any element created on the map, thus allowing for a close relationship between the text and the map. We could also add extra information about each map element in a customizable 
popup box. The georeferencing of historic maps is directly supported in the interface, as is adding a wide variety of geometries. Although the interaction of the various pieces does add complexity, we benefited from the flexibility of the software. The Penn Libraries has been extending this tool, adding functionality for creating a map legend, importing a variety of spatial formats, and for exporting data for reuse in other systems. ${ }^{1}$ This is possible due to the open nature of the Omeka source code base, which allows for expanding functionality through easy modification. These contributions to the community should benefit other Neatline users, further highlighting the benefits of open source software.

\section{MAPPING ASSIGNMENT}

The instructor for the Spatial Analysis class independently developed all course assignments, including the Neatline text mapping task. In addition to the pedagogical motivations discussed above, the purpose of the assignment was to both produce a map that could be shared publicly on the Internet and to support archaeological field research in this region of Anatolia. Because the specific tool we selected had significant influence on the shape of the assignment, the practical details of the assignment were articulated in collaboration with the digital humanities specialists at the library.

The week began with a discussion during class time about the purpose of the exercise and the theoretical considerations of mapping historical texts. The discussion was facilitated by two graduate students, who proposed readings for the class, as well as the instructor. We read two articles: Murrieta-Flores, Donaldson, and Gregory (2017) and Rahman, Zaman, and Hafiz (2016). The former was an example of how literary texts could be studied with the analytical tools provided by GIS while the latter used a variety of documents, such as texts, itineraries, and urban descriptions, to map the spatial extent of a historical urban area. Both readings allowed students to contextualize the process of transforming textual narratives into two-dimensional maps. In particular, the students interrogated the analytical validity of utilizing certain GIS tools, such as k-means clustering and least-cost-path analysis, for interpreting the past. Our subsequent class meeting provided lab time for the students to choose and begin mapping their texts. Library specialists conducted these lab sessions in order to answer technical questions specific to Neatline and Omeka. The assignments were further facilitated by the online tutorials written by two students to guide use of the tool for our specific workflow, as well as by the public documentation made available by the Neatline development team (docs.neatline.org).
We provided each student with a login to Omeka that allowed them access to all parts of the system through the dashboard screen. The next step for the students was for each participant to select their own individual text and conduct primary-source data entry in an unsupervised environment. The only guideline was that the traveler's account should describe the central portion of western Anatolia, with a preference for publications documenting travel prior to the introduction of railroads to the region in the mid-nineteenth century. Students were guided towards Google Books and Archive.org as possible repositories of traveler accounts, and a few illustrative examples were provided for reference. Ultimately, however, we intended for the students to take an active role in the selection, curation, and visualization of their data so as to better replicate future, personal projects. This control also encouraged students to be more discerning throughout the mapping process, as "best practices" had to be formed through individual reflection and use of the Neatline tool. Although students had the option of mapping texts from non-English languages, only one student chose a text in French. This decentralized model of data entry enabled great flexibility for varied experimentation with texts and visualization. Instead of mapping entire texts, however, students mapped only those sections of the texts that covered the region under investigation, usually amounting to just a few pages. The students independently designated which parts of the texts were appropriate and noteworthy for visualization on the map and decided how to visualize them. At the end of the assignment, each student also wrote a paragraph reflecting on the process.

Each map constitutes an "exhibit" in Omeka, which currently prevents participants in the project and the public from viewing multiple accounts as layers on the same map, a desideratum for the future. The public view of a Neatline exhibit is composed of three separate elements: the text

1. For source code, please see the Neatline-related subprojects of this Github group: github.com/upenndigitalscholarship. 
itself, which is shown on the right-hand side of the screen; the map with geometry and popup windows, shown on the left-hand side; and the timeline, which is displayed at the bottom of the screen (Figure 2). Contributors can add new "records" to the map through the Neatline map interface, where they control the popup window information for each record, as well as its geometry and display style on the map and its chronological characteristics for the timeline. Records for our purposes might represent sites, villages, routes, mountain ranges, areas, or bodies of water, among other things. Style options for geometry include type (point, line, polygon), size, color, opacity, default zoom, and additional settings. For this assignment, each student was required to map 30 records, an artificial number meant to ensure a uniform workload.
Neatline records can interlink with a variety of different elements within the website. Omeka itself contains an element type called "item" for managing HTML content, and these items can serve as the content for the popup window associated with a record. Records are identified, and can be navigated to, by unique alphanumeric names called "slugs." Within the exhibit's narrative text, we can add links as HTML <span> tags that use the slug as an attribute to connect to each record. These links are highlighted in grey for display and emphasis within the narrative text (Figure 3). The timeline also links to the records, based on their chronological properties. In this way, the narrative text, timeline, and popups are all interlinked with the records displayed on the map, providing multiple levels of information for the viewer.

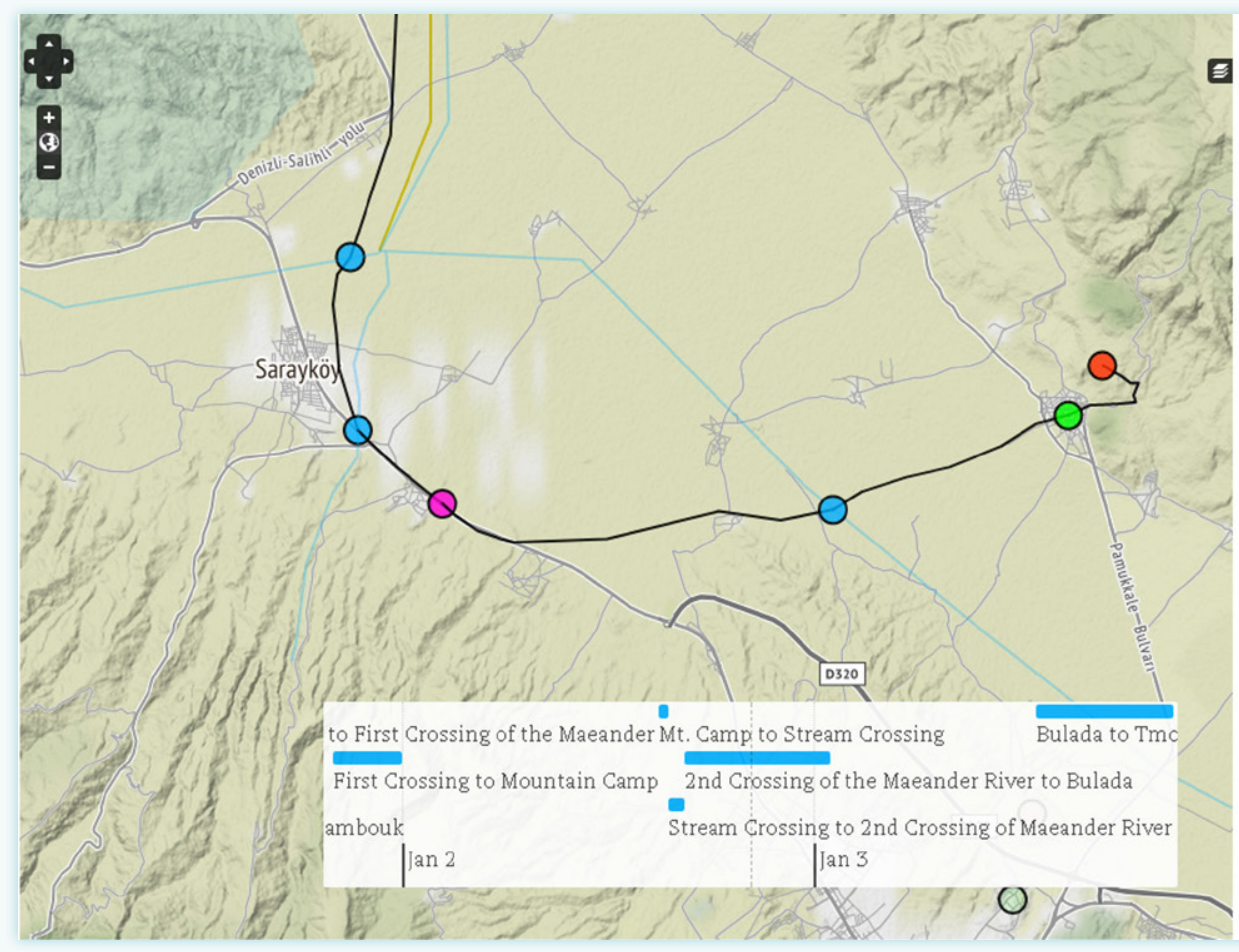

\section{CH. LXXII}

We are now to relate the occasion of our sudden departure from Hierapolis. While we were busy at the theatre, the aga of a village eastward came to bathe with a considerable retinue, and two of his men summoned our janizary to appear before him. He was sitting beneath a wall, in the shade of the large ruin; and among the Turks with him were a couple, whom we had treated on the preceding day with coffee. He alleged, that we had knowledge of hidden treasure, and had already filled with it the provision chests, which he had seen by our tent; and demanded one of them as his share. He treated the janizary as mocking him, when he endeavoured to explain the nature of our errand, and the manner in which we had been employed. The janizary returned to us, exclaiming, as at Eski-hissar, that we were among rebels and robbers; that neither equity, our firhman, or the grand seignior would avail us; that, unless we would repent too late, it behoved us to hasten away,) He was prevailed on, however, to remonstrate again ; but the aga insisted on his claim with threatenings, if we did not speedily comply. It seemed an exorbitant sum would be

Figure 2. Visualization of Richard Chandler's (1825) Travels in Asia Minor and Greece. Various color hues were used to designate feature classes: red represents ancient sites, green contemporary or modern sites, blue the crossings over rivers or streams, and purple the location of a campsite. Map by Jordan R. Rogers.

\section{RESULTS}

Implementing the first stage of the Anatolian Travelers Project as a classroom exercise has provided information on a variety of aspects of the project that have helped us identify future avenues of research and study. We acquired important information about the online mapping process with historical texts, about the logistics of managing the task as a class exercise and of using digital tools in a classroom setting, and about the individual 
experiences of students learning about the past through mapping. Experimentation was enriched by the variety of the students' academic backgrounds and the freedom with which they could each make choices during mapping. Although geographically constrained, the travelers' accounts themselves ranged widely in terms of information recorded and narrative structure. The students each made decisions on the criteria for inclusion of sections of each text and on how to visualize the features mentioned. Since the original authors never intended the mapping of these texts, we encountered some general, overarching issues when mapping the narratives. The students' learning outcomes varied; we determined that some aspects of the assignment were effective, but plan to redesign others in preparation for offering this type of assignment in future classes. Here we revisit the four learning objectives for the assignment, as outlined above, and review how the mapping texts assignment accomplished or fell short in achieving these outcomes. Finally, we consider how the assignment may influence future research projects carried out by the students.

\section{INTEGRATING HISTORY AND ARCHAEOLOGY}

As the primary focus of the class was archaeological, this historical assignment provided a contrast with the other tasks completed during the semester. From a practical perspective, this began with the students selecting the texts they would map. Choosing a text was challenging for students who lacked prior experience with this region or its history, but online tools aided our discovery process. Google Books and Archive.org both contain many scans of pre-twentieth century accounts and enable full-text keyword searches. Students naturally gravitated towards accounts related to their own research interests, and this led to a diversity of text types, ranging from crusader annals (Magoulias 1984), to accounts following the path of the ancient author Xenophon (Ainsworth 1844), to site descriptions of the Seven Churches of Asia (Arundell 1828). For pedagogical purposes, however, it is appropriate to ask whether in future iterations of this assignment, it might not be more beneficial to encourage students to examine accounts outside of their personal research areas in order to facilitate exposure to new information.

Each account offered a different characterization of the spaces in which the author interacted with people, monuments, and the landscape itself. We sought texts that would lend themselves to the relatively easy translation of the narrative into a map, with enough information for visualizing the landscape. Not all accounts, however, contained a linear progression of movement from point to point, and some accounts contained more detail than others about the logistics of travel, such as place names, detailed route descriptions, distances traversed, and the time required for the traveler to move through these spaces.

Considering the varied academic backgrounds of the students involved in the project, treating these historical texts as repositories of data proved non-problematic. The ancient history students appreciated the chance to consider space from a textual perspective, while the archaeology students did not express any concerns about working with historical texts as an evidence type. Instead, a complaint raised by several students was their lack of familiarity with the context of the region-especially local toponyms or the history of visitation. Nevertheless, as most of the students conduct fieldwork in diverse worldwide locations, they recognized the value of the travelers' accounts as additional documentation to support landscape studies. Among the comments submitted by the students reflecting on this assignment, many raised new questions about the spatially and temporally distinct characteristics of this region that they had not previously considered. This appears to be 
influenced directly by their ability to consider the thoughts of the people in the landscape reflected in the writing. One of the more welcome consequences of the assignment was the students' interest in locating and mapping historical accounts for their own regions. By equipping students with both the ability to use online mapping tools and the intellectual apparatus for reflecting on their visualization choices, this assignment has proven to have impacts outside of the classroom.

\section{DIGITAL LITERACY}

Getting students to think critically about digital tools was one of the most successful aspects of the assignment. The students are now aware of the possibility of undertaking a similar project in the future for their own research. Just as importantly, they know what resources are available for their assistance-namely, the digital humanities specialists at the library. Several students in the class have gone on to engage with other digital humanities projects and have become part of the wider digital humanities community at the University. Two students developed extra proficiency with this tool since they had the additional assignment of creating an online tutorial to explain the workflow to their peers. Overall, we experienced almost no technical problems that prevented students from being able to use Neatline on their own. The combination of multiple sources of help-from an in-class lab to the online documentation-facilitated student work on the project. The instructor was also available for answering questions at any time over the Slack messaging platform.

Another important learning outcome of this assignment was the students' exposure to the iterative development lifecycle of digital tools. Neatline satisfied many of our needs, but most students saw opportunities for improvements that would have aided our project. No tool is perfect, and we are very grateful to the Neatline team for their efforts. Nevertheless, the students' ability to communicate requirements to technical specialists is an important component of digital literacy and tool development. The Penn Libraries are currently working on implementing some of these upgrades and will share those enhancements with the community. Perhaps in greatest demand was a map legend that would enable us to display what the colors and shapes indicated for each map. The ability to toggle data layers would also be useful to allow a more dynamic viewing experience and to focus the viewer's attention on certain data. Additional label functionality, through which label size, position, and orientation could be chosen, would be welcome, both within the timeline and on the map. Students also discussed the possibility of bringing our data into a more precise software platform such as ArcGIS Pro for further analysis, so we are interested in seeing the development of a robust data export routine. A final consideration raised by students was the possibility of visualizing multiple maps simultaneously. Since we are producing multiple maps, one for each text, the ability to display these together as layers in a single map view would facilitate comparison between historical accounts and mapping choices made by the students.

Although we utilized the timeline feature in each map, some students also noted that the integration of the temporal dimension with the text and the map remained challenging. First, the timeline required absolute dates, and these were not always provided by the authors. In such cases, the student had to choose an arbitrary start date and assign the remaining days relative to that origin point. Even when the accounts provided temporal data, the occasional nature of their inclusion and their unreliability were readily apparent. Some texts, for example, specified times, while others only specified days. Many texts were inconsistent in how often they recorded time (hours of the day), and some texts did not record time at all. Further, the timeline plugin to Neatline only enables limited customization, leading to limitations in how we could visualize time. For instance, we could only display the time at one temporal scale per map, so if an author switched between reporting hours and days, the timeline would appear to stretch or compress the time.

\section{VISUALIZATION DECISIONS}

A major learning experience from this assignment was the opportunity to consider how we could visualize spatial elements described in a textual narrative on a $2 \mathrm{D}$ map. The Neatline record construct necessitates the partitioning of the continuous narrative into discrete units of data. Students located these units spatially and chronologically, and then decided how to visually represent them on a map in an attempt to reflect the author's original intent in recording the locations and to highlight what they believed to be important for future research aims. The popup box associated with each record enabled the presentation of additional descriptive information. Students 
decided where to separate the data units and how much of the overall narrative to include in the exhibit, as well as, importantly, what to exclude. Some texts fit this model better than others. Linear accounts that provided precise details on sites, routes, and time proved well suited; on the other hand, a text like Ramsay's A Historical Geography of Asia Minor (1890) proved less so, as it consists mainly of an encyclopedic overview of each site, disconnected from its neighbors.

Because students were restricted to mapping only 30 records, this forced them to make decisions about the scale of the elements they would map and their representative geometries. All students visualized named sites-particularly towns, villages, and archaeological ruins-as points, symbolized by small circles on the map. Likewise, lines represented the routes between these "stops." Students tended to map toponyms, because proper names often denote a discrete entity that lines up well with a Neatline record, and because they are easily locatable on other maps, modern or historical. After these basics, the specifics diverge across our initial maps. Some maps include polygons of various shapes and sizes to visualize mountain ranges, lakes, islands, and entire geopolitical regions. Other students mapped ill-defined areas, including mountain ranges, with a point, symbolized by shapes including circles and triangles. Some students traced rivers as blue lines, though this was an arduous task, and these are hopefully already available from an Internet source as reusable geometry. The students often dealt with relative spatial relationships during the mapping process, where an author might indicate, for instance, that a certain place is located to the "left" of another place. These indications guided placement of the points and lines.

Symbol color in Neatline could easily be changed, allowing it to serve a variety of purposes, from differentiating sites visited from those only discussed, to separating horse-traversed routes from railroads, to distinguishing villages from natural features. Setting the transparency of geometries also enabled a better view of the basemap and offered another strategy for differential visualization. In terms of basemaps, students found the Stamen Terrain map (maps.stamen.com) to be most useful for viewing the landscape, as was OpenStreetMap for finding named locations. Kiepert's (1890) historical maps also helped guide the work, and could be used as a background via Mapwarper's Web Map Service interface. ${ }^{2}$

Sometimes students had to deal with specific peculiarities in an author's work. For example, in Richard Chandler's (1825) travel narrative, he points out what he believes is a previous traveler's incorrect description of the Maeander River's course. Chandler himself, however, appears to misidentify this river. The student digitizing this text recognized this inconsistency and chose to create a line geometry record, separate from the true Maeander River, to communicate this error to the viewer and show the discrepancy between Chandler's perception and the actual location. The choice to include this particular misattribution, among others, demonstrates the distance between representation and reality and emphasizes the interpretative element of transferring prose narrative into discrete data points.

From a pedagogical perspective, we found that providing creative freedom to the students was a successful aspect of this assignment. Students had a chance to make specific choices on how to visualize the various elements of the text. The choices were limited significantly by the tool, but the range of solutions they developed reflects their increasing digital skillset and diverse ideas. More importantly, it generated a thoughtful discussion about what "best practices" might be for mapping any historical text with Neatline. Although useful for the classroom setting, the variety of visualization approaches still presented a challenge to our ultimate goal of map publication. Our experiments will continue, but at this point we can suggest an initial set of standards for visualizing places in new texts. Points serve well to map locations such as villages, ancient ruins, and landmarks. They can also be used to document more ephemeral places important to the journey, such as river crossings or camping locations. Different shapes and colors can separate out different classes of places (Figure 2). Routes can be marked with thick, transparent lines to reflect uncertainty while still indicating connections. Natural features discussed in the text can be marked with less obtrusive, semitransparent colors. Mountain ranges can be indicated with edgeless polygons, and rivers with light blue lines. Such visualization selections might change in different situations, such as to conform to other basemaps. The initial zoom level for each element should

2. For example: http://maps.nypl.org/warper/maps/27383\#Export_tab. 
center on that element, but should be zoomed out far enough to relate the location to other parts of the text.

\section{PERSPECTIVES ON SPACE}

The hardest learning outcome to measure considers how students' conceptualization of space changed as a result of the assignment. We were likewise very interested in understanding how their ideas developed about past peoples' thoughts on space. As archaeologists and historians, we these two levels of perception are in fact deeply interconnected. Only through examining specific examples of observations made by individual students can we begin to approach an understanding of what they learned. These observations demonstrate the range of ways the students engaged with intersections of textual narrative and space. Interestingly, they also highlight how the students considered each traveler's own perspective on these landscapes as well.

While attempting to map Elliott's (1838) Travels in the Three Great Empires of Austria, Russia, and Turkey onto a contemporary road map, one student observed how differently the same place appeared to people who inhabited different mental worlds. The student was forced to navigate the distinction between primarily Biblical and classical place names provided in the travel account and the modern Turkish toponyms on the online map. The latter set of names might have been used locally in the nineteenth century, but the traveler's writing evidenced different priorities: Elliott was traveling through an ancient landscape superimposed upon the contemporary landscape. He rarely acknowledged that he was doing so, and so this process was not evident to the reader. Coming to this insight does not necessarily require mapping out the text, but the exercise established this fact clearly by forcing the student to explicitly consider how the author referred to the geography. On the other hand, the student found it relatively easy to locate most of the classical place names, reflecting the traveler's interests. For the most part Elliot was not trying to depict the region as it was in his own time, with its major Ottoman centers and landmarks. The Ottoman places were often locations the traveler passed through and referred to in offhand observations. These were typically minor villages that never achieved great historical importance and therefore may be absent from modern maps of the region. The Greek, Roman, and early Christian sites were, by contrast, genuine tourist sites, sanctified by their antiquity, and thus much easier for even a twenty-first-century reader to identify. Ultimately, these geographic practices make the Ottoman stratum of the landscape in Elliot's account fade even further into the background.

Another student recognized that certain elements of the landscape as described by his traveler required further research given the traveler's lack of interest in those particular features. In Thomas Smith's (1678) ethnographic travel account, Remarks upon the Manners, Religion, and Government of the Turks, he describes a castle near the ancient site of Sardis. At this castle, Smith chose to discuss only the ancient inscriptions preserved within the structure. Yet the castle in question was in fact a later Byzantine structure that employed reused ancient materials in its construction as spolia. When the student realized this, it completely changed his understanding of the space, its history, and the author's interaction with it.

In moving from the fluidity of the narrative texts to the structure of the records, no topic was more prominent in the minds of students than uncertainty. Multiple students made observations regarding the difficulties of mapping space when data were omitted by the travelers, such as precise route descriptions. Today such data might be gathered using satellite positioning systems with meter-level accuracy, but these texts cannot provide such detail. Locational information in a historical account often lacks clarity for a variety of reasons. Many factors can influence the author's description of the space, such as not having visited a place and relying solely on information from other sources, or even the author's desire to be deceptive in their presentation of space. Furthermore, the landscape itself has changed, especially due to twentieth-century industrialization, including the damming and control of rivers that previously flooded seasonally. The students experimented with a number of different visualization strategies to deal with the challenges of these uncertainties. There was a tendency to trace the modern road network when drawing route lines, thus applying the assumption that the historical and modern paths are similar. Some students indicated uncertainty by employing a range of different colors. Other students added question marks to the popup and timeline labels when the location was unclear. Perhaps the most useful strategy was to utilize the popup box itself to discuss the data, allowing for a more comprehensive presentation of the challenges and their possible solutions (Figure 4). 


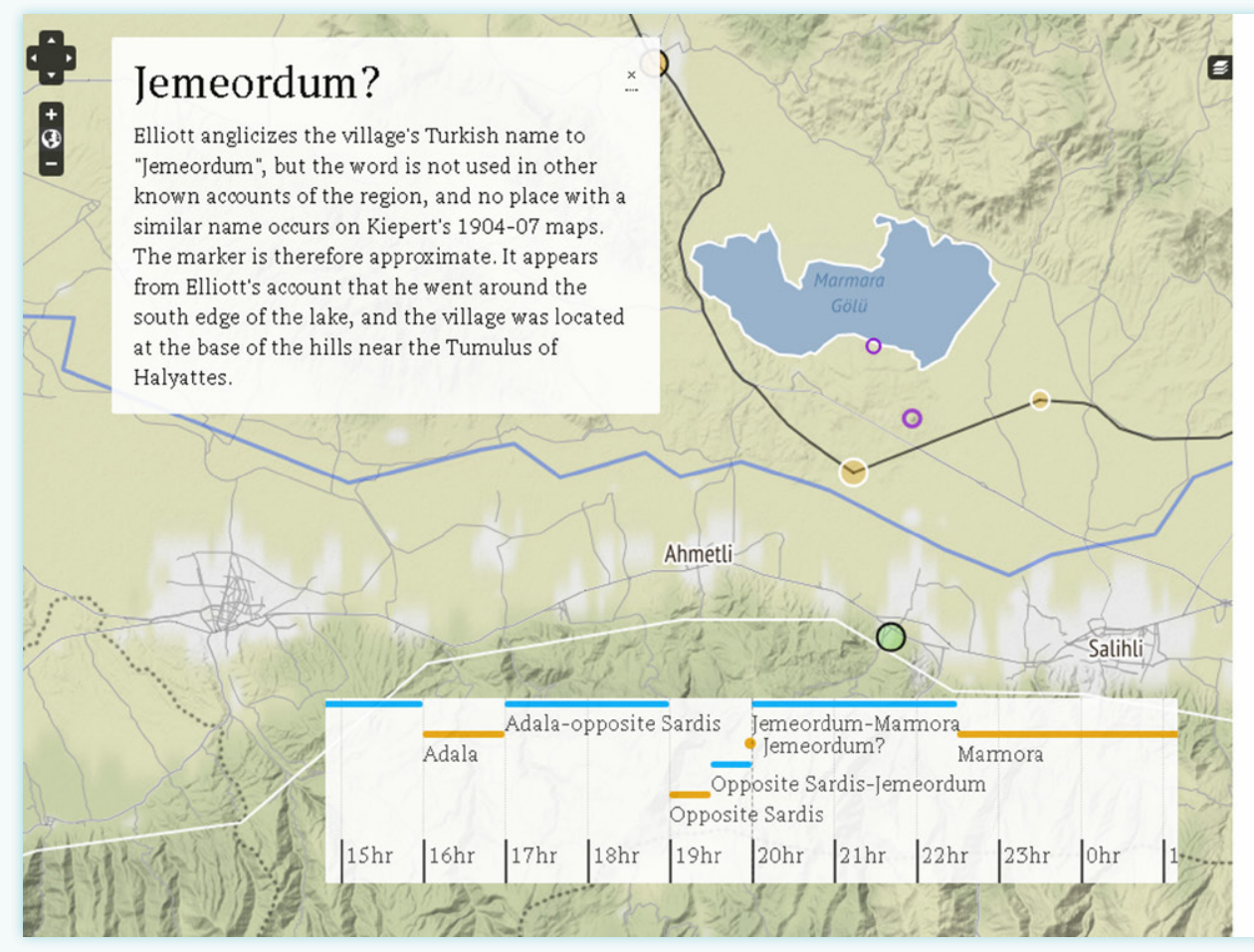

manifest her divine power by working miracles; and the veneration entertained for the sacred edifice may account for the number of tumuli in the vicinity, as the Lydians might naturally have desired that their bones should rest under the immediate eye of their tutelary goddess.

Between Adala and Mamora there is only a single village, called Jemeordum, standing at the foot of the range opposite Tmolus; the huts built of mud, with flat roofs and without windows, look in the distance like children's baby-houses. In front of these were a number of little mounds, resembling dwarf barrows, which we were informed were heaps of hay and straw covered with earth to protect them from the weather. Throughout this day's journey we saw not a single caféné except at Adala, and met scarcely a human being on the road. No strings of camels varied the monotony of the way, which lies over barren wastes producing nothing but a dry weed with seed like that of the dandelion, and a few brambles scorched and withered, as though their roots were struck in ashes. The hills surrounding the plain are equally sterile; one range is known by the name of "The dry mountains," from its utter destitution of vegetation. A few oxen, a single camel browsing, a wild dog in full chase after a

Figure 4. Question mark and discussion concerning the location of Jemeordum in Charles Elliott's (1838) Travels in the Three Great Empires. Map by Bryn Ford.

Given the course's previous focus on GIS software, multiple students contrasted this assignment with previous classwork using the tools provided in ArcGIS. In general, it is possible to use digital tools either to assist in a careful reading of the texts themselves or to engage in computationally driven analysis of the journeys the texts depict. However, these two goals require different tools. One virtue of our project was that the text-centered Neatline interface provided a platform for the former approach, giving us new ways to visualize the authors' literary landscapes-perhaps bringing us closer to the human aspect of the data than traditional quantitative GIS techniques. Accordingly, students tended to approach the maps in this fashion, focusing more on the "qualitative" rather than the "quantitative." Nonetheless, the latter approach still has much to offer, and we envision that combining quantitative techniques with the data collected in the Neatline platform could open new avenues of research.

Students also observed that rivers appear in the texts as both conduits and obstacles, as can be seen in the various difficulties in crossing them (see Figure 2). Most travelers mentioned rivers frequently, usually since they were central to their navigation through the river valleys of western Anatolia. Students recognized the rivers as part of the planes of movement and networks of locations that could be missed without a close reading and mapping of these travel texts. Multiple students found it valuable to map and consider the spatial relationships between the places that travelers visited as opposed to those they saw from a distance and those that they mention were nearby, but did not see-this is similar to the approach taken by Murrieta-Flores, Donaldson, and Gregory (2017) in mapping the English Lake District. This aids our understanding of individual motivations and conceptions of space, allowing researchers to go beyond the simple quantitative approach to mapping discrete points. In the end, this must all be judged against the fact that most of these authors actually did visit this real landscape.

Another student's map highlighted how engagement with the landscape varied according to the mode of travel. Davis's Anatolica, written in 1874 as the railroad was expanding into the interior of Anatolia, recounts a journey that mixed train and horseback travel. The student chose to visualize this with contrasting colors, making rail routes black and horseback routes red. The student also used points to represent each location mentioned in Davis's narrative. The resulting map (Figure 5) shows a remarkable increase in point density when Davis transitions from train to horseback. The student observed that the author engaged much more closely with the landscape from 


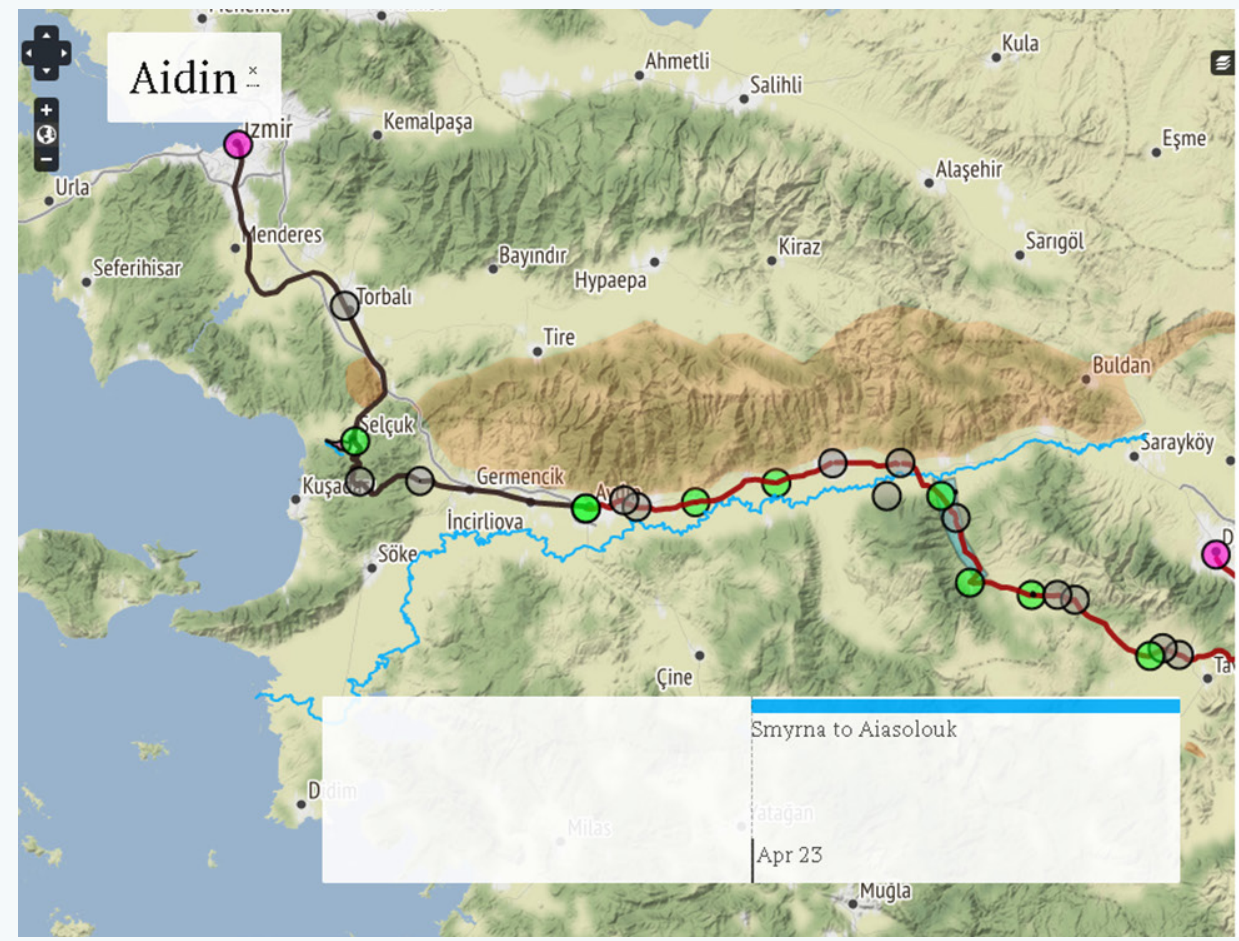

beautiful. The chain on the north side, a part of Mount Messogis, is nugged and broken ; it is a succession of peaks green and wooded to the summits, their outlines most fantastic, yet singularly beautiful. At Karabounar the top of Baba Dagh (Mount Cadmus), covered with snow, first appears.

6. At 1 P.M. we reached Aidin. The modern city lies on the edge of the plain, close under the lowest slopes of Messogis ; the ruins of ancient Tralles are on the high plateau above the town; but neither then, nor on our return, had we time to visit them.

7. Mr. Bradech, of Aidin, who was to be the leader of our party, had our horses ready, and at 3.30 P.M. we started for Nazli. The plain of the Maeander is the finest district of Anatolia, fertile, well cultivated, and with abundance of wood and water There is even a good road, enclosed with walls and well-kept hedges in most parts.

8. Our route was as follows:-4.25 P.M., Imamkeui - near this is a large mineral spring; 5 P.M., Sekkeui ; 5.49 P.M., River Kutchak ; 6.15 P.M., Keuschk ; here we halted half an hour for refreshment. We halted again at Aktcha Keui,

Figure 5. At the city of Aydin (map center), John Davis disembarks the train and proceeds east on horseback through western Anatolia, visiting significantly more sites along the way, according to his 1874 work, Anatolica. Map by Helena Dominguez Del Triunfo.

the latter mode of transport, and this added engagement translated to much richer detail in the text. This conclusion can be reached simply by looking at the map generated in Neatline, but the investigation can now be pursued in a quantitative fashion. With data from more texts, it might be possible to demonstrate in statistical form how substantially the railroad affected travelers' experiences of the landscape.

Multiple students reflected on the time dimension as part of this project. As mentioned above, we struggled with implementing time given the timeline's limitations and textual variety. One student wondered whether there might be a better way to understand and visualize the relationship between real time and narrative time. For example, does the amount of text written about a place reflect the amount of time spent at that place? Another student noticed that night and day would have been experienced quite differently by the travelers. She wondered if they actually experienced two landscapes, at odds with one another? For example, could extenuating circumstances, like the activity of "bandits," differ depending on the time of day? These types of questions did not result from our other archaeology-focused exercises in the class. We believe this reflects the importance of the students' interactions with the firsthand accounts of people in the historical landscape.

The project increased interest in further research on the routes for all students. This in turn encouraged additional interest in the class about the various approaches of landscape archaeology, in order to understand the differences between, for example, ancient Roman and modern road networks, or to investigate non-normative movement through the landscape, such as by pastoralists (Aston and Rowley 1974; Arbuckle 2012). One potentially fruitful approach would be further analyzing how people saw their surroundings on the ground, a process often studied with viewshed analysis in GIS, based on accurate digital elevation models of the terrain. We would like to try to compare these analyses with the travelers' accounts to see if visibility of places made a difference in travelers' decision-making.

\section{FUTURE DIRECTIONS}

We FOUND THE PEDAGOGICAL OPPORTUNITY of the Anatolian Travelers Project valuable in encouraging discussions about technological decision-making, the methods of map visualization, perceptions of space, and 
the choices made by each student. This process of active mapping offered the students an opportunity to consider the valuations of space found in our texts and the difficulty of mapping those in truly representative ways. For classroom purposes, these discussions were an essential reflective exercise that pushed the students to think critically about space and to engage with theoretical and practical readings on the topic. We hope that a similar meta-narrative can be presented to public internet viewers of our maps in some way, such as through discussions of uncertainty, as mentioned above.

We have also reflected on how we might approach the assignment differently during another offering of the class. We would probably foreground questions about the historical landscape more explicitly. When a traveler moves through a landscape that seems to be full of history, where are these memories concentrated and how do they interact with or obscure the contemporary reality? Ideally, we would make better use of the chronological functionality of Neatline. Perhaps conceptualizing the temporal dimension historically would allow a different perspective that lets us think more about the role of memory in landscape. Plotting the timeline of the travelers' itineraries was important, but we also would like to find ways to capture their thoughts about time and space. There is also the possibility of color-coding different parts of the landscape based on the ancient periods that each traveler saw in them. For example, in some locations, a traveler may prioritize the Roman past, while in a different location, an Iron Age culture might be of more interest. In this way, the traveler not only moves through his (or, rarely, her) own time, day-to-day or hour-to-hour, but he also moves through historical periods in his mind, and we would like to find a way to visualize this.

The class provided several means of support for the students to be able to learn to use Neatline and create a map. However, most students were unable to produce a final product that was ready for online publication. The main constraint was, of course, time, since the assignment took place over only a single week. There was much for the students to do, from selecting a text, to finding the correct passage, to learning the tool, to making decisions about how to represent the text on the map. Without dedicating additional time to this particular assignment, and thus taking time away from building other skills, it would be difficult to develop fully finalized maps. Students in later classes, together with volunteers and a work-study student, were ultimately able to prepare ten maps for online presentation (openarchaeology.org/anatoliantravelers).

Here we have focused on the pedagogical aspects of our initial steps in the project. As the project proceeds, we hope to be able to also write about our reflections on the research results. In practical terms, the next step for the Anatolian Travelers Project involves further engagement from volunteers, students, and researchers in creating a larger dataset. This will enable us, and others, to use the data to diachronically explore the past in this region. By making all of these maps public, we hope both to provide a resource for other researchers and to encourage the further sharing of data amongst scholars. Finally, the open publication of these data in visual form and the results gleaned from them should serve as an excellent way to engage the public in this region's past through a new way of conceptualizing and visualizing these travels.

\section{ACKNOWLEDGEMENTS}

We thank the Penn Libraries, and especially Laurie Allen and Josh Berg, for supporting the web infrastructure for this project. The work outlined here would not have been possible without the pedagogical context of the Center for the Analysis of Archaeological Materials (CAAM) at the Penn Museum. Sami Suppes and Rory Palmer helped finalize many of the maps on the website. Lauren Aguilar helped lead the weekly class on this topic and created a tutorial to guide the students. We thank everyone who worked on creating maps: Petra Creamer, Helena Dominguez Del Triunfo, Emily French, Travis Lumpkin, Greg Maslow, Malkia Okech, Kristen Pearson, Janelle Sadarananda, John Sigmier, Michelle Terng, and Paul Verhelst. Finally, we express our appreciation for the valuable suggestions of two anonymous reviewers who helped us to focus and improve this article. 
Ainsworth, William F. 1844. Travels in the Track of the Ten Thousand Greeks. London: John W. Parker. https:// archive.org/embed/travelsintrackt00ainsgoog.

Alexander, Neal. 2015. “On Literary Geography.” Literary Geographies 1 (1): 3-6. https://www. literarygeographies.net/index.php/LitGeogs/article/ view/1-2.

Arbuckle, Benjamin S. 2012. "Pastoralism, Provisioning, and Power at Bronze Age Acemhöyük, Turkey." American Anthropologist 114 (3): 462-476. http://doi. org/10.1111/j.1548-1433.2012.01446.x.

Arundell, Francis V. J. 1828. A Visit to the Seven Churches of Asia; with an Excursion into Pisidia. London: John Rodwell. https://archive.org/details/ visittosevenchur00arun.

Aston, Michael, and Trevor Rowley. 1974. Landscape Archaeology: An Introduction to Fieldwork Techniques on Post-Roman Landscapes. London: Newton Abbot.

Beckman, Gary. 2016. "Ahhijawa und kein Ende: The Battle over Mycenaeans in Anatolia." In Tavet Tat Satyam: Studies in Honor of Jared S. Klein, edited by Andrew M. Byrd, Jessica DeLisi, and Mark Wenthe, 1-12. Ann Arbor, MI: Beech Stave Press. https://deepblue.lib.umich.edu/bitstream/ handle/2027.42/133091/FsJKlein.pdf.

Brown, Vincent. 2015. "Mapping a Slave Revolt: Visualizing Spatial History through the Archives of Slavery." Social Text 33 (4 (125)): 134-141. http://doi. org/10.1215/01642472-3315826.

Brughmans, Tom. 2013. "Thinking Through Networks: A Review of Formal Network Methods in Archaeology." Journal of Archaeological Method and Theory 20 (4): 623-662. http://doi.org/10.1007/s10816-012-9133-8.

Caquard, Sébastien, Stephanie Pyne, Heather Igloliorte, Krystina Mierins, Amos Hayes, and D. R. Fraser Taylor. 2009. “A 'Living' Atlas for Geospatial Storytelling: The Cybercartographic Atlas of Indigenous Perspectives and Knowledge of the Great Lakes Region.” Cartographica 44 (2): 83-100. http:// doi.org/10.3138/carto.44.2.83.
Caquard, Sébastien. 2011. "Cartographies of Fictional Worlds: Conclusive Remarks." The Cartographic Journal 48 (4): 224-225. http://doi.org/10.1179/00087041 1X13203362557264.

. 2013. "Cartography I: Mapping Narrative Cartography.” Progress in Human Geography 37 (1): 135-144. http://doi.org/10.1177/0309132511423796.

Chandler, Richard. 1825. Travels in Asia Minor and Greece. Oxford: Clarendon Press. https://archive.org/ details/travelsinasiami00revegoog.

Cobb, Elvan. 2018. "Mixing Time: Ancient-Modern Intersections along the Western Anatolian Railways." In Producing Non-Simultaneity - Construction Sites as Places of Progressiveness and Continuity, edited by EikeChristian Heine and Christoph Rauhut, 185-201. London: Routledge.

Cobb, Peter J. 2016. “Computational Analyses of Archaeological Ceramics: The Second Millennium BCE Ceramics of the Marmara Lake Basin in their Western Anatolian Regional Context." PhD diss., University of Pennsylvania. http://repository.upenn. edu/dissertations/AAI10190311.

Connolly, James, and Mark Lake. 2006. Geographical Information Systems in Archaeology. Cambridge: Cambridge University Press.

David, Bruno, and Julian Thomas. 2008. Handbook of Landscape Archaeology. New York: Routledge. http:// doi.org/10.4324/9781315427737.

Davis, Edwin J. 1874. Anatolica; or The Journal of a Visit to some of the Ancient Ruined Cities of Caria, Phrygia, Lycia, and Pisidia. London: Grant \& Co. https:// archive.org/details/anatolicaorjourn00davi.

Débarre, Ségolène. 2016. Cartographier l'Asie mineure. Leuven, Belgium: Peeters Publishers.

Dryer, Kaitlyn. 2012. "Mapping the Text of Lilith: Macdonald's Labyrinths and Gardens.” North Wind 31: 65-94. http://digitalcommons.snc.edu/northwind/ vol31/iss1/6. 
Earley-Spadoni, Tiffany. 2017. "Spatial History, Deep

Mapping and Digital Storytelling: Archaeology's

Future Imagined Through an Engagement with the

Digital Humanities." Journal of Archaeological Sciences

84: 95-102. http://doi.org/10.1016/j.jas.2017.05.003.

Elliott, Charles B. 1838. Travels in the Three Great

Empires of Austria, Russia, and Turkey, Volume II.

London: Richard Bentley. https://archive.org/details/ travelsinthreegr02elliiala.

Eltis, David. 2007. "A Brief Overview of the TransAtlantic Slave Trade." Voyages: The Trans-Atlantic Slave Trade Database. https://archive.slavevoyages.org/ assessment/essays.

Evans, Courtney, and Ben Jasnow. 2014. "Mapping Homer's Catalogue of Ships." Literary and Linguistic Computing 29 (3): 317-325. http://doi.org/10.1093/1lc/ fqu031.

Hones, Sheila. 2017. "Literary Geography." In The International Encyclopedia of Geography, edited by Douglas Richardson, Noel Castree, Michael F. Goodchild, Audrey Kobayashi, Weidong Liu, and Richard A. Marston, 4065-4071. New York: John Wiley \& Sons. http://doi. org/10.1002/9781118786352.wbieg0312.

Huffman, Daniel P. 2018. “A Freelancer's Approach to Teaching Cartography," Cartographic Perspectives 90: 82-85. http://doi.org/10.14714/CP90.1491.

Kahn, Andrew, and Jamelle Bouie. 2015. "The Atlantic Slave Trade in Two Minutes: 315 Years. 20,528 Voyages. Millions of Lives.” Slate, June 25, 2015. http://www.slate.com/articles/life/the_history_of_ american_slavery/2015/06/animated_interactive_of_ the_history_of_the_atlantic_slave_trade.html.

Kiepert, Heinrich. 1890. Specialkarte vom westlichen Kleinasie. Berlin: D. Reimer. http://digitalcollections.nypl.org/ items/95d525da-59dc-96a8-e040-e00a18066a71.

Knowles, Anne K. 2002. Past Time, Past Place: GIS for History. Redlands, CA: ESRI Press.
Külzer, Andreas. 2016. "Byzantine Lydia: Some Remarks on Communication Routes and Settlement Places." In Trade in Byzantium: Papers from the Third International Sevgi Gönül Byzantine Studies Symposium, edited by Paul Magdalino and Nevra Necipoğlu, 279-295. Istanbul: Koç University Press.

Landry, Donna, and Gerald MacLean. 2012.

"Introduction: On the Road in Anatolia, and Beyond." Studies in Travel Writing 16 (4): 337-348. http://doi.org /10.1080/13645145.2012.727228.

MacEachren, Alan M. 1995. How Maps Work: Representation, Visualization and Design. New York: Guilford Press.

Magoulias, Harry J. 1984. O City of Byzantium: Annals of Niketas Choniates. Detroit: Wayne State University Press. https://archive.org/details/o-city-ofbyzantium-annals-of-niketas-choniates-ttranslatedby-harry-j-magoulias-1984.

Mellink, Machteld J. 1966. "Anatolia: Old and New Perspectives." Proceedings of the American Philosophical Society 110 (2): 111-129. http://www.jstor.org/ stable/985744.

Muri, Allison. 2016. "Chapter 14: Beyond GIS: On Mapping Early Modern Narratives and the Chronotope." Digital Studies / Le champ numérique 6. http://doi.org/10.16995/dscn.11.

Murrieta-Flores, Patricia, Christopher Donaldson, and Ian Gregory. 2017. "GIS and Literary History: Advancing Digital Humanities Research Through the Spatial Analysis of Historical Travel Writing and Topographical Literature." Digital Humanities Quarterly 11 (1). http://www.digitalhumanities.org/ $\mathrm{dhq} / \mathrm{vol} / 11 / 1 / 000283 / 000283 . h t m 1$.

Purves, Alex C. 2002. Telling Space: Topography, Time and Narrative from Homer to Xenophon. PhD diss., University of Pennsylvania. https://repository.upenn. edu/dissertations/AAI3043943.

Rahman, Mashrur, Kawser Bin Zaman, and Roxana Hafiz. 2016. "Translating Text into Space for Mapping the Past Territory of a City: a Study on Spatial Development of Dhaka During Mughal Period." City, Territory and Architecture 3 (7). http://doi.org/10.1186/ s40410-016-0036-y. 
Ramsay, William M. 1890. The Historical Geography of Asia Minor, Royal Geographical Society, Supplementary Papers, Volume IV. London: John Murray. https:// archive.org/details/historicalgeogra01rams.

Robert, Louis. 1980. A travers l'Asie Mineure: poétes et prosateurs, monnaies Grecques, voyageurs et Géographie. Athens: École Française d'Athènes.

Rusert, Britt. 2017. "New World: The Impact of Digitization on the Study of Slavery." American Literary History 29 (2): 267-286. http://doi.org/10.1093/alh/ ajx003.

Sack, Carl M. 2018. "The Status of Web Mapping in North American Higher Education," Cartographic Perspectives 89: 25-43. http://doi.org/10.14714/ CP89.1429.

Said, Edward. 1978. Orientalism. New York: Pantheon Books.
Saunders, Angharad. 2010. "Literary Geography: Reforging the Connections." Progress in Human Geography 34 (4): 436-452. http://doi. org/10.1177/0309132509343612.

Stoneman, Richard. 2015. "How Many Miles to Babylon? Maps, Guides, Roads, and Rivers in the Expeditions of Xenophon and Alexander." Greece and Rome 62 (1): 60-74. http://doi.org/10.1017/S0017383514000242.

Smith, Thomas. 1678. Remarks upon the Manners, Religion, and Government of the Turks. London: Moses Pitt. http://name.umdl.umich.edu/A60582.0001.001.

Torget, Andrew J., Rada Mihalcea, Jon Christensen, and Geoff McGhee. 2011. "Mapping Texts: Combining Text-Mining and Geo-Visualization to Unlock the Research Potential of Historical Newspapers." White Paper, University of North Texas. https://digital. library.unt.edu/ark:/67531/metadc83797. 